\title{
Scripting as a pedagogical method to guide collaborative writing: university students' reflections
}

\author{
Kirsi Heinonen ${ }^{1 *}$ D, Nore De Grez ${ }^{2}$, Raija Hämäläinen ${ }^{1}$, Bram De Wever ${ }^{2}$ and Sophie van der Meijs ${ }^{1}$
}

\author{
* Correspondence: kirsi.m. \\ heinonen@jyu.fi \\ ${ }^{1}$ Department of Education, \\ University of Jyväskylä, P.O. Box 35, \\ Fl-40014 Jyvaskylä, Finland \\ Full list of author information is \\ available at the end of the article
}

\begin{abstract}
A collaboration script is a set of instructions used to improve collaborative learning among students in technology-enhanced environments. Previously, university students' perspective has been under-represented in the study on collaboration scripts. In this article, we focus on understanding students' experiences in a scripted collaborative writing task, especially from the perspective of following the script. The study was conducted among undergraduate students $(N=91)$ taking a master-level educational science course at one university each in Finland and Belgium. Divided into 25 groups, each with three to five members, the students worked on collaborative writing tasks. During their shared writing process within these groups, all students were introduced to a four-phase simultaneous sequential integrating construction script (SSCIS). Then, data from the students' reflection notes on the collaborative writing process were analysed. The thematic analysis revealed that over half of the students highlighted how the introduced script provided them with appropriate support for the writing process; therefore, they used a script-based collaborative writing approach (52\%). However, almost as many students (48\%) viewed the script as inadequate or even impeding their accomplishment of the mutual writing task; therefore, they chose to deviate from it. In this group of students decided not to follow script-based writing engaged in the collective writing approach (32\%), characterised as free form compared to sequential script-based writing. Other students opted for the separate writing approach (16\%), leading them to divide the writing assignment into single parts among the group members and to compose the text without authentic collaboration. By focusing on students' individual reflections, the findings of our study suggest that to enhance script-based learning processes, it is essential to provide guidance for the implementation of the script, additional content-related support or tailored choices.
\end{abstract}

Keywords: Collaborative writing, Computer-supported collaborative learning, Technology-enhanced learning, Higher education

\section{Introduction}

In higher education (HE), collaborative writing is a widely used pedagogical approach that aims to prepare students for their future working life by promoting generic skills, such as collaboration, creativity and critical and reflective thinking (Hodges 2002;

(c) The Author(s). 2020 Open Access This article is licensed under a Creative Commons Attribution 4.0 International License, which permits use, sharing, adaptation, distribution and reproduction in any medium or format, as long as you give appropriate credit to the original author(s) and the source, provide a link to the Creative Commons licence, and indicate if changes were made. The images or other third party material in this article are included in the article's Creative Commons licence, unless indicated otherwise in a credit line to the material. If material is not included in the article's Creative Commons licence and your intended use is not permitted by statutory regulation or exceeds the permitted use, you will need to obtain permission directly from the copyright holder. To view a copy of this licence, visit http://creativecommons.org/licenses/by/4.0/. 
Jääskelä et al. 2018). Web 2.0 technologies offer novel and flexible opportunities to develop collaborative writing interventions by means of technological tools, which intend to facilitate student groups' ability to co-write and edit each other's texts, share information, produce and combine new knowledge and collaborate in different ways (Aydin and Yildiz 2014). Although current studies on HE have identified several positive consequences of applying the collaborative writing approach in technology-enhanced learning (TEL) settings (e.g. Ellis and Goodyear 2013; Ertmer et al. 2011; Storch 2005), in practice, there have been divergent results concerning students' experiences with such an environment (De Wever et al. 2015). Learning exclusively through technology requires students to possess multifaceted skills; combined with the collaborative writing approach, this makes the learning process even more complex for students. Therefore, ensuring that students engage in productive, high-level and collaborative processes in TEL settings remains a significant challenge (e.g. Hämäläinen 2012; Fischer et al. 2013b).

\section{Collaborative writing as a learning method}

The first serious discussions and analyses on collaborative writing emerged during the late 1980s when Mackler (1987) found that, according to co-authors, group efforts facilitated a better outcome than individually produced documents. Ede and Lunsford (1990) described collaborative writing as a social process that challenged the collaboration partners through (1) meaningful interaction during all stages of writing, (2) sharing of decision making and responsibility for the written product and (3) a single text as the product of collaborative writing. Later, Posner and Baecker (1993) proposed a detailed taxonomy of the collaborative writing process. They characterised joint writing in terms of four central elements: roles, activities, methods for document control and writing strategies applied during the process.

In this article, collaborative writing denotes the process of producing a common written document (Storch 2005) through shared planning, researching, writing, editing and reviewing by multiple authors (Posner and Baecker 1993). Definitions of collaborative writing share the idea that the collaboration comprises alternate phases of writing and interacting with partners. Computer-supported collaborative writing incorporates the key pedagogical idea of computer-supported collaborative learning (CSCL). In short, CSCL is a pedagogical approach where learning takes place via social interaction (Dillenbourg 1999; Dillenbourg et al. 2009). Specifically, collaborative writing creates a learning experience that constructs social and cognitive activities through interaction (Li 2013).

Collaborative writing is 'an iterative and social process that involves a team focused on a common objective that negotiates, coordinates and communicates during the creation of a common document' (Lowry and Nunamaker 2003, p. 12). From the students' perspective, collaborative writing is recognised as a highly complex process and has been subjected to a wide range of studies. However, there are few clear answers about the best strategy to employ for a collaborative writing task. Additionally, there is no clear understanding of how a specific group adopts a particular strategy or strategies and how these evolve during the writing process (Onrubia and Engel 2009). Although collaborative writing is a promising and widely used teaching method in HE contexts, 
different challenges can be distinguished. Collaborative writing has been recognised as a highly demanding task since individual and collaborative cognitive and metacognitive processes are interwoven (Marttunen and Laurinen 2012). Developing truly collaborative writing processes (Mayordomo and Onrubia 2015) and conducting particular collaborative writing activities, such as revising, have proven to be very challenging (Wichmann and Rummel 2013). For example, prior studies have claimed that some students experience it as awkward to revise or comment on other students' written thoughts in a collaborative wiki environment (De Wever 2011; Kale 2014). Although in the CSCL context, the critical role of social interactions in successful collaboration has been emphasised (e.g. Kobbe et al. 2007; Vogel et al. 2016), earlier research suggests that simply involving students in collaborative learning settings through technology does not automatically ensure pedagogically beneficial interactions among students (Hämäläinen and Häkkinen 2010). Thus, there is a need to support students in their collaborative writing processes.

\section{Scripting as a method to promote students' collaboration}

Instructional scaffolding, a process designed to support a certain learning activity, has been recognised as a way to generate successful collaborative learning. Over the last decade, several studies have illustrated the positive effects of socio-cognitive scaffolding via collaboration scripts, especially in HE contexts (e.g. Kobbe et al. 2007; De Wever et al. 2015; Fischer et al. 2013b; Rau et al. 2017; Vogel et al. 2017). A collaboration script is a set of instructions used to improve collaboration among students during the learning process. In practice, the advantages of collaboration scripts are typically described as promoting the reason for students' interaction in collaborative learning settings (Fischer et al. 2013a; Kollar and Fischer 2007; Rummel and Spada 2005). In this light, scripting has been applied in various ways, and previous studies have indicated that the collaborative writing process can be facilitated by dividing it into particular phases and assigning students tasks or roles related to each phase in order to support the creation of a jointly written document (e.g. De Wever et al. 2015; Heimbuch et al. 2018). Additionally, scripting can be used to specify the roles that students are expected to adopt during collaboration processes or to trigger the roles that are relevant for high-level learning activities (e.g. resolving socio-cognitive conflicts; see Strijbos and Weinberger 2010).

In this study, we applied the simultaneous sequential integrating construction script (SSICS) (De Wever et al. 2015), which aimed to enhance collaboration and shared responsibility among the students. The SSICS is a pedagogical model that engages students in an authentic collaborative process of shared knowledge construction through sequencing task-based activities and delineating specific roles to achieve a shared responsibility of an entire collaborative task (De Wever et al. 2015). Before starting to accomplish their co-authored writing task, the small groups were advised that the idea behind the script was to provide them with a general precept for collaborative working and writing but did not require precise adherence to it (Dillenbourg and Tchounikine 2007).

The students were introduced to the four-phase SSICS procedure as follows: student 1 in each small group started at phase 1 (state-of-the-art), student 2 at phase 2 
(advantages), student 3 at phase 3 (disadvantages) and student 4 at phase 4 (attention points for drawing conclusions) (Fig. 1). The first phase (state of art) required each of the students had to read the mandatory source together with one additional source and start writing a draft for this specific part of the collaborative document. The second phase (advantages) required students to evaluate what aspects of the theoretical ideas or empirical evidence can be well applied. The third phase (disadvantages) demanded students to focus on critical points of view or empirical evidence. At the end, the forth phase of the script called for students to identify the main points of their task and ensure that the main points were well-balanced. After 1 week of working on a particular phase, the students were rotated in the following manner: student 1 moved to phase 2, student 2 moved to phase 3 , etc. This required their reading more sources in order to proceed to the next phase. In the subsequent phases, the students were asked to revise the drafts written earlier by their fellow students with regard to their phase-specific perspective. In this way, they advanced through the four phases that were meant to inspire them to edit other group members' texts in order to take responsibility for all aspects of the mutual writing assignment and therefore engage thoroughly in the collaborative writing process.

The main aim of the SSICS procedure presented here intended to coordinate students' joint writing by associating it with collaborative text production, in which new content creation is founded on the former output (Arvaja et al. 2007; Kobbe et al. 2007) of the co-authors. In practice, the SSICS script guided students in such a way that, during the first phase of the script, they each had to read different information sources and begin writing a draft for one specific section of the collaborative writing project. In the subsequent phases, students were required to read several more sources and then were asked to revise the drafts made earlier by their fellow students. This script thus stimulated the students' collaboration instead of just presenting a means for dividing the work. SSICS was labelled 'sequential integrating', given that students should successively contribute to the text and propose justified modifications (Onrubia and Engel 2009) and 'simultaneous' since each of them should start with one section. The SSICS has been shown to be beneficial in increasing shared responsibility and influencing the degree to which a task is addressed (for the number of sources studied and amount of time spent on the task, see De Wever et al. 2015).

Notwithstanding the positive consequences of scripting (Fischer et al. 2013b), there is still no guarantee that scripting axiomatic leads on intended ambition in collaborative learning settings. Other research on the effectiveness of CSCL scripts has also reported

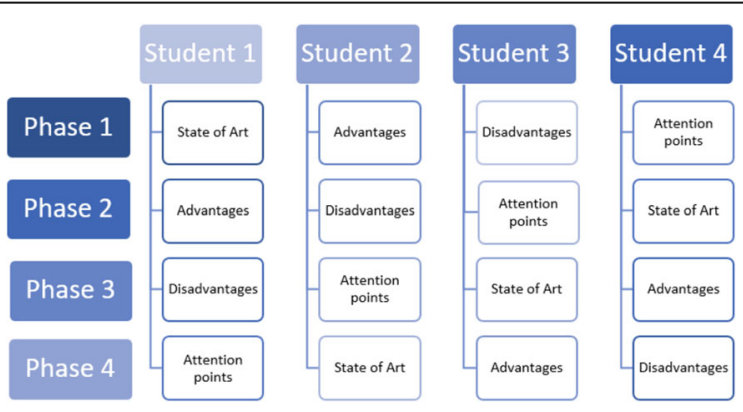

Fig. 1 Overview of the four phases introduced in the SSCIS (modified from De Wever et al. 2015) 
negative findings. For example, Raes et al. (2016) have found no significant improvement that could be attributed to the classroom script intervention. Other studies on CSCL have identified the 'over-scripting' issue, where students considered the introduced script as excessively restricted and therefore declined to work according to it (Dillenbourg 2002; Dillenbourg and Hong 2008). In other cases, students reported that the script did not offer them sufficient support in relation to the script level, leading to the 'under-scripting' problem (Dillenbourg and Hong 2008; Weinberger et al. 2009). Finally, previous studies on CSCL scripts have identified a possible divergence between the ideal script and the actual, realised script (Dillenbourg and Jermann 2007; Papadopoulos et al. 2013). Despite significant attention to the outcomes of scripted collaboration and collaboration processes among students (see the review by Vogel et al.), the ways that students experienced the scripted collaborative task and how these experiences are associated with their decisions on how to proceed with the task have been somewhat neglected. In this respect, appropriation of scripts has recently garnered attention (Stegmann et al. 2016; Tchounikine 2016).

A script can be perceived as an artefact of which learners develop an understanding, and appropriation is the process by which learners perceive, understand and make the script theirs (Tchounikine 2016). To make sense of these pedagogical challenges that may arise when integrating scripts into collaborative learning settings (Häkkinen and Mäkitalo-Siegl 2007), it is indispensable to gain new knowledge on how students experience and appropriate the introduced external scripts. Given that students' experiences with the scripts may shed light on why scripts are followed or disregarded, it is important to investigate such experiences. Our study addresses this twofold research question: How did the university students experience the collaborative scripted tasks in relation to (a) the kinds of writing approaches they applied and $(b)$ the key restrictions and resources affecting these approaches?

\section{Methods}

\section{Context of the study}

The study involved undergraduate students from one Finnish university and one Belgian university. The participants were taking an optional master-level course in educational sciences $(N=91$; Finland, $N=47$ and Belgium, $N=44)$. In total, 95 students participated in this study, but afterwards 91 students reflected their joint writing process detailed enough and therefore used for final analysis. The demographics of the participants are reported in Table 1.

Table 1 Demographics of the participants $(N=91)$

\begin{tabular}{|c|c|c|c|c|c|c|}
\hline \multirow[t]{2}{*}{ Characteristic } & \multicolumn{2}{|c|}{ Finnish University $(N=47)$} & \multicolumn{2}{|c|}{ Belgian University $(N=44)$} & \multicolumn{2}{|c|}{ Total $(N=91)$} \\
\hline & Percentage & $N$ & Percentage & $N$ & Percentage & $N$ \\
\hline \multicolumn{7}{|l|}{ Age } \\
\hline 29 years or less & 62 & 29 & 95 & 42 & 78 & 71 \\
\hline 30 years or more & 38 & 18 & 5 & 2 & 22 & 20 \\
\hline \multicolumn{7}{|l|}{ Gender } \\
\hline Male & 15 & 7 & 9 & 4 & 12 & 11 \\
\hline Female & 85 & 40 & 91 & 40 & 88 & 80 \\
\hline
\end{tabular}


Both interventions were designed and executed according to the same guidelines. The similar conditions for the interventions endeavoured to assure close cooperation between the responsible professors and teachers in both universities. Therefore, the course design, execution and grading procedure for the collaborative assignments were discussed thoroughly before, during and after the interventions. In both universities, the students were randomly assigned to three- to five-member groups that worked together on collaborative writing tasks for 12 weeks. Students were divided into 25 groups (Finland, $N=14$ and Belgium, $N=11$ ), in which 6 groups consisted of 3 students, 18 groups comprised 4 students and 1 group had 5 students. During their joint writing process in the groups, all students were introduced to follow the four-phase SSICS procedure. The teachers and the small groups met in class for $2 \mathrm{~h}$ per week, and the students worked together out-of-class on a joint writing assignment online or face-to-face. They were allowed to decide on their working practicalities in their respective groups and to use as much time as they needed to accomplish the required task. Although the content of the specific courses varied, the students in both universities were all involved in a task with a similar structure and writing requirement, consisting of a recommendation paper (12-15 pages) on a specific subject (wikis, collaboration or sense making) with an in-depth focus on how educational practitioners could use these ideas in developing their work.

All groups wrote the text by using Web 2.0 technologies, that is, a shared Google Docs document or Moodle's Wiki tool. All students were instructed to follow a four-phase SSICS procedure based on a script used by De Wever et al. (2015), in which the collaborative writing task was divided into different phases to support the students' collaboration (Dillenbourg and Tchounikine 2007; Kollar et al. 2006). In this study, the idea of the SSICS is to guide the groups step by step in co-producing their papers by following particular guidelines through the rotation system. In our previous study, we focused on the effects of the SSICS on students' learning processes (based on collaborative knowledge construction) and outcomes (De Wever et al. 2015; De Grez et al. 2017). This present study goes one step further by focusing on students' experiences and how these are associated with their decisions on how to proceed with the scripted CSCL task. Therefore, after the intervention, all students were individually asked to write reflection notes about their experiences during the scripted, computer-supported collaborative writing task.

\section{Data collection and analysis}

Students were asked to produce a written document that reflected on the following guiding questions: (1) What did you do during the complete process of writing the paper? Through which steps did your work proceed? (2) What went well, and what proved to be a challenge? How do you explain this? (3) Please explain how students who will take this course next year-and will thus collaborate on a similar task-should proceed in order to collaborate successfully (Rummel et al. 2009). They were asked to individually write at least 300 words on each of the guiding questions and hand in their reflection notes at the conclusion of the course. They wrote their reflection papers electronically and submitted them through the learning management system. To obtain reflections that would be as authentic as possible, these papers were not graded. All students involved in the study were required to sign informed consents. 
We analysed the students' reflective writings using the qualitative thematic analysis approach in an inductive manner (see Braun and Clarke 2006). An iterative analysis process was conducted by the first author in close association with the second and the fifth authors. All authors participated in definitive cross-checking of the emerging themes and subthemes. We used the following techniques to assure rigour: (1) The data were collected from similar scripted tasks in both universities and underwent the same collection process. (2) Investigator triangulation was used, with three investigators participating in the applied analysis process (Patton 2001). (3) The collaboratively developed codebook used systematic, data-driven analysis. (4) The participants' abundant written reflections were used to support the results. To identify thematic patterns across the data, our analysis process was carried out in accordance with Braun and Clarke's (2006) guidelines and proceeded through the following six main phases.

(1) Becoming familiar with the data. To engage with the entire data set, the students' reflective writings were read and re-read actively to identify the prevalent topics concerning the scripted collaborative writing task in technology-enhanced environments from the university students' perspective. By highlighting the potentially meaningful information, the initial ideas were noted for the next phases of the analysis. This phase revealed that four participants had not reflected on their scripted collaborative writing process in the light of the research question; thus, their reflection notes were omitted, and the remaining data set $(N=91)$ was included in the subsequent analysis.

(2) Generating the initial codes. Two researchers separately coded $16 \%$ of the data set with an inductive approach by obtaining all content that was pertinent to the students' reflections from the vantage point of the research question. We first formulated the initial codes on whether the students indicated that they had applied or deviated from the introduced script. Descriptions of how the students had tackled the task individually and as a group, in relation to the script, were included under the first codes. Another set of codes was created for clarifications of why the students decided to apply or deviate from the script. To ensure agreement on the appropriate codes, the two authors jointly and critically reflected on the coding. The structured codebook was developed as a result of the reflective discussion. It included 92 initial codes labelled with a few words or short sentences, such as 'struggling in the beginning', 'deviated from the script' and 'followed the script'. To identify all potentially relevant meanings of the students' reflections, individual extracts were coded as many times as possible throughout the data set. Furthermore, the process involved collating the initial codes with relevant extracts to identify meaningful patterns.

(3) Searching for themes. In this phase, similar codes were collated under potential themes and relevant subthemes. This iterative process entailed multiple rounds of profound reading of the data and examining the relationships between divergent codes in the light of how university students reflected on scripted collaborative writing. The meaningfully sorted codes represented three broader themes-script-based, collective writing and separate writing approaches-each consisting of subthemes that were constructed by analysing the properties of individual codes within them. In this process, 18 subthemes were identified. Table 2 illustrates an example of codes applied and themes and subthemes identified by way of a short data section.

(4) Critically reviewing the themes. The potential themes were critically reviewed in conjunction with their relevant subthemes to confirm the codes' internal homogeneity 
Table 2 Data extract, with codes and identified theme and subthemes

\begin{tabular}{|c|c|c|c|}
\hline Data extract & Coded for & Theme & Sub-theme \\
\hline $\begin{array}{l}\text { We ended up not switching the roles. There are a } \\
\text { couple of reasons behind this. We started the process } \\
\text { a little late because of group merging. At the first } \\
\text { meeting, we didn't feel ready to switch. At the time of } \\
\text { the next meeting, we had so many other courses } \\
\text { causing workloads that we felt better not to cause } \\
\text { more stress. Because of our different writing and } \\
\text { reference styles, we found it difficult to produce text } \\
\text { together. Most of the text we produced individually } \\
\text { and later combined'. }\end{array}$ & $\begin{array}{l}\text { 'Not followed the } \\
\text { script' } \\
\text { 'Not rotated' } \\
\text { 'Difficulties in group } \\
\text { merging' } \\
\text { 'Script-based } \\
\text { working as stressful } \\
\text { method' } \\
\text { 'Different writing } \\
\text { and referencing } \\
\text { styles' } \\
\text { 'Difficulties to } \\
\text { produce text } \\
\text { together' } \\
\text { 'Separate writing' } \\
\text { 'Produced text } \\
\text { individually' } \\
\text { 'Produced text } \\
\text { individually' } \\
\text { 'Combined text } \\
\text { later' }\end{array}$ & $\begin{array}{l}\text { Separate } \\
\text { writing } \\
\text { approach }\end{array}$ & $\begin{array}{l}\text { 'Difficulties in } \\
\text { grouping' } \\
\text { 'Difficulties to } \\
\text { produce text } \\
\text { together' }\end{array}$ \\
\hline
\end{tabular}

and external heterogeneity (Patton 2001). The first and the second authors reexamined the themes that emerged in phase 3, which aligned with the coded extracts throughout the data set. The authors individually rechecked all the extracts within the potential themes and re-evaluated their correspondence with each other and in light of research question. A triangulated review was conducted in accordance with the framework, based on data-driven classification of the data.

(5) Qualifying and naming the themes. Through joint negotiations, all authors agreed on the final themes and subthemes. The process aimed to determine which aspects of the data represented each of the three main themes and 18 subthemes. The authors ensured that the invoked themes and subthemes had an exceptional focus were not overlapping and directly addressed the research question (Braun and Clarke 2012).

(6) Writing the final report. Finally, to produce a compelling overall report on the research findings, analytical descriptions of the relevant data extracts were incorporated to reveal important insights on the research context (the participants' names are pseudonyms).

\section{Results on approaches to scripted collaborative writing}

A thematic analysis of the students' reflective writings identified three main themes (script-based, collective and separate writing approaches) and 18 subthemes (see Table 3) regarding the scripted collaborative writing task in the technology-enhanced environment. Each small group approached the writing task in a group-specific way; some groups followed script-based writing, while others customised or deviated from the proposed script. The students who applied script-based writing highlighted several positive consequences of following the SSICS procedure, such as providing the structure and the organisation for working and writing, as well as ensuring equal involvement in the joint writing process. The students who characterised their mutual writing process as collective used the free-flow writing strategy and the group members' abilities rather than the structured support of the SSICS. The students who employed the 
Table 3 Summary of the emerging main themes and subthemes

\begin{tabular}{|c|c|c|}
\hline Main themes & Subthemes & Data examples \\
\hline \multirow{6}{*}{$\begin{array}{l}\text { 1. Script-based } \\
\text { writing } \\
\text { approach }\end{array}$} & $\begin{array}{l}1.1 \text { Script as advisable and straightforward } \\
\text { working method }\end{array}$ & Respecting the system [= rotation] is thus advisable'. \\
\hline & 1.2 Script guides and organises & $\begin{array}{l}\text { It [= script] created structure and clarity what every group } \\
\text { member had to do at each moment'. }\end{array}$ \\
\hline & 1.3 Script ensures equal involvement & $\begin{array}{l}\text { Because of this [= script], the contribution and } \\
\text { responsibility of each member came forward'. }\end{array}$ \\
\hline & $\begin{array}{l}1.4 \text { Script supports editing, commenting and } \\
\text { completing others' texts }\end{array}$ & $\begin{array}{l}\text { From the second step, we gave comments and edited one } \\
\text { another for expanding our ideas and perspectives in terms } \\
\text { of the topic'. }\end{array}$ \\
\hline & $\begin{array}{l}1.5 \text { Script supports conjoining divergent writing } \\
\text { styles }\end{array}$ & $\begin{array}{l}\text { The rotation system was a huge plus for the essay. The } \\
\text { different writing styles are matching and the text reads as } \\
\text { a whole'. }\end{array}$ \\
\hline & $\begin{array}{l}1.6 \text { Additional agreements support script-based } \\
\text { writing }\end{array}$ & $\begin{array}{l}\text { We soon discovered we would be more successful if we } \\
\text { checked other's work often'. }\end{array}$ \\
\hline \multirow{6}{*}{$\begin{array}{l}\text { 2. Collective } \\
\text { writing } \\
\text { approach }\end{array}$} & 2.1 Free-flowing writing & $\begin{array}{l}\text { I think the whole process was more free-flowing rather } \\
\text { than consciously structured'. }\end{array}$ \\
\hline & $\begin{array}{l}2.2 \text { Group (e.g. group dynamics) as a resource } \\
\text { for joint writing }\end{array}$ & I think we were also lucky to get this kind of group'. \\
\hline & 2.3 Individual interests as resources for writing & $\begin{array}{l}\text { This resulted in dividing the work according to our own } \\
\text { interests'. }\end{array}$ \\
\hline & 2.4 Skill-based individual responsibilities & $\begin{array}{l}\text { We divided the tasks again. We took into account the } \\
\text { talents of each member'. }\end{array}$ \\
\hline & $\begin{array}{l}2.5 \text { Script as meaningless/aimless writing } \\
\text { method and difficult to follow }\end{array}$ & $\begin{array}{l}\text { '....we discovered that it was more convenient to not follow } \\
\text { the rotation system anymore'. }\end{array}$ \\
\hline & $\begin{array}{l}2.6 \text { Writing and revising whole document } \\
\text { together online/face-to-face }\end{array}$ & $\begin{array}{l}\text { We came together to discuss about the given feedback } \\
\text { and adjust our text'. }\end{array}$ \\
\hline \multirow{6}{*}{$\begin{array}{l}\text { 3. Separate } \\
\text { writing } \\
\text { approach }\end{array}$} & 3.1 Script as inconsistent writing method & $\begin{array}{l}\text { '...all of us were fairly inactive with this paper, as we did not } \\
\text { know how to continue writing the paper'. }\end{array}$ \\
\hline & 3.2 Inadequate planning and poor organisation & $\begin{array}{l}\text { Hereabout we did not make good agreements and this } \\
\text { resulted in chaos'. }\end{array}$ \\
\hline & $\begin{array}{l}3.3 \text { Different group sizes in relation to four- } \\
\text { phase script }\end{array}$ & $\begin{array}{l}\text { First, we worked to our steps, but after one member left us } \\
\text { and we more focused to part which we started with'. }\end{array}$ \\
\hline & 3.4 Difficulties in producing text together & Editing a single text all together was not a good idea'. \\
\hline & 3.5 Difficulties in grouping & $\begin{array}{l}\text { But it was a challenge because our group did not really } \\
\text { bond, and we never got that close-knit feeling of belong- } \\
\text { ing to the same group'. }\end{array}$ \\
\hline & $\begin{array}{l}\text { 3.6 Script did not provide guidance for working } \\
\text { collaboratively in technology-enhanced } \\
\text { environment }\end{array}$ & $\begin{array}{l}\text { I think it was hard to work on Google Drive because I } \\
\text { never really knew what I was expected to do'. }\end{array}$ \\
\hline
\end{tabular}

separate writing strategy viewed the SSICS as hampering the accomplishment of the mutual task and therefore decided to split the writing task into detached portions among the group members. Furthermore, the results indicated the factors that played an important role for the students in either following or deviating from the proposed script. Each main theme, together with the subthemes (highlighted in italics and identified by their numbers in parentheses), will be further elaborated in the following sections.

\section{Tackling the collaborative writing task by applying the external script: script-based writing approach}

Based on the results, $52 \%$ of the students ( 47 of 91) noted that they had applied the proposed external script to their collaborative task by following the script-based sequential writing strategy. Typical for this pattern, the students reported positive consequences when using the script to complete a joint writing assignment. The following 
excerpt shows how Matilda viewed applying the collaborative script as an advisable and straightforward working method (subtheme 1.1) in which the initial phase was essential and formed a foundation for the co-writers' forthcoming work:

I would recommend students follow the rotation system. It is an easy way of working. But it is important to take the first step with a lot of care. The first step is the basis the other students will proceed on. (Matilda)

When describing their approach, the students pointed out that the external script guided and organised their collaborative writing process (subtheme 1.2). The script directed them to strive for a common understanding about the tangible accomplishment of the task, thus setting an aim for their joint writing assignment. Kristian reported how the script supported their collaboration by inspiring his group members to plan and discuss their joint task purposefully in the early phases of the writing process.

The first step for our group and us as individuals was to try to understand what the task was all about. We all read through all the instructions and information that was available by ourselves and then discussed how each of us understood them. We also presented many questions for other members of our group. (Kristian)

In this approach, the participants emphasised the affirmative effects of the script and found that it enhanced the group members' equal involvement (subtheme 1.3) in the collaborative writing process. First, the students stated that the script supported them in tackling the task as a group. Following the script-based rotation system through the four phases encouraged them to complete one others' work during their collaborative writing process. By applying the script, all group members felt more able to align their input and create a coherent text together. In the following example, Klaara highlighted how the script provided an explicit distribution of the work and the roles, which called for all her group members' equal participation in writing the assignment.

Concerning the writing process, the rotation system was a good and practical method. It was my first time working like this, but I will definitely use it in the future. It created structure and clarity on what every group member had to do at each moment. Because of this, the contribution and responsibility of each member came forward. (Klaara)

When describing their approach to script-based writing, the students reported that the script guided their efforts towards genuine collaborative writing. Hence, writing activities, such as editing, commenting and completing the text produced by others (subtheme 1.4), were viewed as forming an integral part of the writing process, in which the proposed script played a crucial role to promote fertile group practices regarding the co-creation of a new text. The students who followed the script emphasised encouragement and edited their colleagues' writings without hesitation. Lukas described how applying the script rapidly accustomed his group members to revising one others' texts and forming their ideas based on previous work. 
After the first rotation of roles, editing the writings of the others felt a bit clumsy, but quickly we got used to it. The above-mentioned encouragement for the text editing gave us the courage to edit others' texts. Although we had agreed with what kind of information was needed to search for in each role and finding information was not difficult, it was pleasantly easy to take a little model of what others had already written and build ideas on them. (Lukas)

Additionally, the students who applied the script believed that the script-based circulation system assisted them considerably in conjoining their divergent writing styles (subtheme 1.5). Hence, they noted that the script supported them in creating a consistent shared text together. Although they reported examples of their initial apprehension about merging significantly different study experiences in academic writing and writing styles, they felt that the proposed script eventually ensured the production of a wellwritten, uniform and coherent document. Marie cited her extremely positive stance towards the script-based writing approach and characterised how the introduced script offered accountability to all group members and helped them amalgamate divergent writing styles into one streamlined document:

The rotation system was a huge plus for the essay. The different writing styles are matching and the text reads as a whole. You feel more responsible for the whole essay, instead of being responsible for just one part of the essay. (Marie)

Although the students reported following the proposed script, a few (13\%; 12 of 91) mentioned the variety of additional agreements that they made and/or modifications to the script. These additional agreements (subtheme 1.6) proved to support their collaborative writing. The students experienced their consensus on particular methods of profound reading and identifying significant knowledge, as well as the application of such methods was beneficial for the collaborative accomplishment of the task. They made additional agreements on the timetable to enable all group members to complete their writing on time. Therefore, supporting their writing colleagues empowered them to slightly modify the script, as Thomas described:

At first, we all worked on our topic individually, asking for help when necessary; however, we soon discovered we would be more successful if we checked other's work often or at least when our phase was finished in order to avoid repetition throughout the recommendation, to know the structure of the rest of the text, and to contribute if necessary with information found. (Thomas)

\section{Tackling the collaborative writing task by deviating from the external script: collective writing approach}

Our results revealed that nearly one-third of the students (32\%; 29 of 91) consistently emphasised writing collectively but stated that they actively revised or deviated from the proposed script. Typical for this pattern, the students highlighted the significance of group dynamics, supporting and complementing one another during the writing process. First, they reported examples of how they used a free-flowing collaborative writing approach 
(subtheme 2.1) rather than a sequential scripted writing technique. They expressed how, as a group, they were more successful by ignoring the script-based sequential writing approach and instead engaging in free-floating collective writing. For example, Silja portrayed how her group collectively settled on an unattached writing approach:

We discovered that it was better to stop following the proposed rotation system. Instead, we chose to work with the articles we were reading. We gave every group member the freedom to complete every part of the paper with relevant information. (Silja)

The students who mentioned that they accomplished their mutual writing task by exploiting free-flowing technique focused on enhancing the most inadequate properties of the co-authored text by utilising their group resources (such as group dynamics; subtheme 2.2). In contrast, students emphasised their group members' individual interests as resources for collaborative writing (subtheme 2.3). In this light, Adrien described how deviating from the proposed script led his group to develop an apposite self-script:

This was also the time we started to diverge from the original script. In my opinion, we started to work according to what is the most important need or deficiency of our text. This resulted in dividing the work according to the deficiencies of the text, and on the other hand according to our own interests. ... However, I think the whole process was more free-flowing rather than consciously structured (even though there was some kind of script). I think we came up with a good self-script that worked well in this context, with these specific people and our group dynamics. I think we were also lucky to get this kind of group. (Adrien)

Other students demonstrated how they deviated from the script by permitting their group members to write from the perspective of their individual strengths. Furthermore, they reported how their collaboration evolved from following the introduced script to free-flowing collaborative writing. Thus, they rejected the rotation system and allowed their group members' unique skills to emerge in their assigned of responsibility (subtheme 2.4), as reflected in Saara's statement:

We divided the tasks again. We took into account the talents of each member. Somebody else and I were better in writing, so we read all parts and processed the feedback ... In short, the finalizing of the paper was our duty. Another group member checked the (in-text) references and, if necessary, adjusted them. (Saara)

Moreover, the students felt that the proposed script was difficult to follow (subtheme 2.5), especially in the early phases of the writing process, or hard to understand from the perspective of completing the collaborative writing assignment. Matias demonstrated how their experience of jointly writing the script substituted for writing comprehensively together:

We did not do any interchange of the roles, as was instructed. We tried this once, but ended up writing the essay comprehensively together. The reason for that could be that at first we didn't understand what we were doing and especially that we didn't have time for all interchanges of the roles. (Matias) 
Other students noticed that the script did not sufficiently support them in writing a smooth shared text as a group. When they recognised that some of their group members were struggling with joint writing, they experienced the proposed script to be meaningless (subtheme 2.5) and therefore opted out of following the script instructions. They reported a variety of examples concerning difficulties in writing together. Some group members were unable to write their parts, while rotating and writing styles differed radically in some groups. Helena portrayed how these difficulties resulted in ditching the proposed script:

The next time that we came together, some of us were finished with their part while others were not. Some group members told which difficulties they encountered. We gave each other tips and referred to articles. In this way, we discovered that it was more convenient to not follow the rotation system anymore. (Helena)

Another student reported writing the whole document together (subtheme 2.6), face to face and/or online by focusing on specific aspects of the text. Kaarina described this approach as follows:

After round two of the rotations, we switched to revising every part. At first, we did this by posting online comments and suggestions, but very quickly, we decided that it was easier to revise it face to face. During the face-to-face time, we revised different things. We paid attention to the cohesion of the text, substantive and correct transitions and smooth transitions, correct language use etc. (Kaarina)

\section{Tackling the collaborative writing task by deviating from the external script: separate writing approach}

Our results indicated that 16\% (15 of 91) of the students disallowed the proposed script in order to end up with the separate writing approach, where dividing the joint writing task into separate parts was essential instead of collaborative sequential writing. When the students did not know how to proceed with the scripted task appropriately and effectively, they ended up deviating from the script. They felt that the presented script method was inconsistent writing method (subtheme 3.1) for writing together. Lotte outlined how the script offered insufficient support for the group to tackle the joint collaborative task:

Our group started the writing process by following the given script-the four steps. However, after the first week, all of us were confused and overwhelmed with our assigned task ... In our work, we saw a lot of overlapping ideas and summaries of the required article. For the next two weeks, all of us were fairly inactive with this paper, as we did not know how to continue writing the paper ... The outline served as our new script. We divided the writing task so that every member was responsible for at least one part of the essay ... Editing a single text all together was not a good idea. We spent too much time with not much efficiency. (Lotte)

Furthermore, inadequate planning and poor organisation (subtheme 3.2) of the activities in the early phases of the shared writing process were reported as key reasons for deviating from the script. These included tackling the group work without common 
agreements concerning working practicalities, organising the written document or even discussing hardly anything related to the group task. When the students experienced the lack of structure and agreement, they decided to allocate separate portions of the writing task to each group member. In some groups, inadequate planning caused difficulties with collaboration, as conveyed by Kalle:

Everybody got a part: a state of the art, advantages and disadvantages, attention points and recommendations. Originally, we started working according to the rotation. Hereabout we did not make good agreements and this resulted in chaos. That is why we changed our approach and decided that everybody checked their sources for useful information. (Kalle)

The students experienced it challenging to follow the script when their group composition suddenly changed, such as when some members dropped out of the course and left the group. Ruben demonstrated how the divergent group sizes in relation to the number of script phases (subtheme 3.3) forced them to change their writing strategy in midstream and settle on the separate writing approach in which each student was responsible for one part of the assignment:

First, we worked to our steps, but after one member left us and we more focused to part which we started with (extension, editing) and added few sentences to conclusion. (Ruben)

The students also provided examples of the difficulties they had encountered in text production as a group (subtheme 3.4). Leena illustrated her experience concerning the complexity of generating shared text, as follows:

We ended up not switching the roles... Because of our different writing and reference styles, we found it difficult to produce text together. Most of the text we produced individually and later combined. (Leena)

When the students experienced difficulties in grouping (subtheme 3.5), such as forming linkages between their group members in the beginning of the writing process, they readily rejected the sequential writing style and chose a more individual text production approach in which separately written parts were combined into a complete document. Moreover, the students reported that regardless of their group, they worked individually on their joint writing assignment. Martta described how they worked together but practically alone:

We did our group work quite independently even though we were a group; each one of us always had their own part and we did not talk much to each other about the subject of group work. (Martta)

In this light, the students reported examples of how they worked individually on their own parts by sharing their work online. In such cases, the students identified themselves as more attuned to individual rather than collaborative working strategies. Justin described their separate writing process as follows: 
All the members of our group worked very individually—probably because we all were used to individual work. As a group, we did not discuss that much; we worked on Google Drive and shared our work online. Our group worked more like a team, where everyone had their own task to complete; it never really reminded me of actual group work. (Justin)

As indicated in the above example, the script did not provide students with adequate guidance when working as part of a group in a technology-enhanced environment (subtheme 3.6). Additional guidance was necessary, as Justin explained:

I think the idea of this course is good: providing possibilities to work on a demanding task in a group. But it was a challenge because our group did not really bond, and we never got that close-knit feeling of belonging to the same group, partly because we hardly ever saw each other in real life-we worked online almost the whole time. I think it would be a good idea to give the group members a little more to go on at the beginning of the task. (Justin)

\section{Discussion}

To date, students' perspectives have been under-represented in studies on CSCL scripts. Therefore, this study focused on understanding university students' experiences in scripted collaboration and how their experiences were associated with the decisions they made during a CSCL writing task. We found that three divergent methods were employed: script-based, collective and separate writing approaches. The students who followed the script-based writing strategy emphasised its positive consequences. The students who applied the collective writing strategy preferred free-flow writing and viewed their group as an essential resource for accomplishing the required task and therefore decided to disregard the script-based writing. Similarly, the students who used the separate writing approach deviated from the script to split the writing task into separate portions among the group members. Over half of the students (52\%) reported following the script-based writing approach. They indicated that the script enhanced their collaboration, organised their writing process and ensured the production of a consistent written document. However, nearly as many students (48\%) encountered difficulties in following the proposed script and therefore deviated from it when tackling the writing assignment.

At the general level, scripting seemed to enhance students' collaborative writing by introducing the reason for interaction (Kobbe et al. 2007; Fischer et al. 2013a; Kollar and Fischer 2007; Rummel and Spada 2005; Vogel et al. 2017). Fifty-two percent of the students indicated a positive stance towards the proposed script. In their reflections, the students pointed out that the SSICS promoted their collaboration by triggering shared interaction (see Hämäläinen and Häkkinen 2010) and ensuring equal involvement of all group members. Furthermore, they highlighted that the script challenged and encouraged them in collaborative text production, editing, commenting on and extending their co-writers' ideas. Despite this positive finding, 32\% of the students experienced the SSICS as meaningless and reported that they deviated from the script and focused on a more free-form collective writing approach. The findings of our study illustrated that encountering difficulties while endeavouring to write together led her 
group to stop following the rotation system. The group members' different levels of ability to produce the text together contributed to their reflections on the script and played an essential role in their deviation from it. Thus, instead of the guidance of the proposed script, they leaned on group dynamics and other students as resources for shared group work (see Arvaja 2012). In such cases, the students viewed script-based writing as intrusive and limiting and accordingly rejected it (cf. over-scripting in Dillenbourg 2002; Dillenbourg and Hong 2008). Additionally, the students who rejected the proposed script and therefore engaged in a collective approach reported that they developed a self-script to accomplish the joint writing task. These interpretations and their resolutions represented how scripting collaboration could lead to script appropriation by students, that is, their personal enactment of the proposed script (Tchounikine 2016).

Finally, the findings revealed that $16 \%$ of the students applied the separate writing approach, which emerged as they endeavoured to accomplish the writing task individually rather than collaboratively. According to the students' interpretations, they deviated from the given script by allocating separate segments of the writing task to each group member. These students indicated that difficulties in the early phases of the writing process (i.e. group composition, the lack of effective communication or adjustments in the number of group members) influenced their decision to proceed with separate writing strategies. In this light, the results are in accordance with previous findings indicating the ineffectiveness of some scripts and potential moderators, such as transactivity, the script level, that is, under-scripting (e.g. Dillenbourg and Hong 2008; Weinberger et al. 2009), additional content and context-related support (Sadler 2004). In this regard, our findings suggest that the starting phase of the task proved to be essential (see also Kollar and Fischer 2007); therefore, it is crucial to provide guidance in implementing the script. Furthermore, the findings indicate that the students need to find common ground not only in the beginning (Tan 2018) but also during the execution of the task. In line with previously described moderators of the effectiveness of CSCL scripts (Vogel et al. 2016), such as additional content-related support, the latter seems to be an essential element of scripting. Thus, it is necessary to provide content-related support without hampering the students' motivation by providing sufficient choices, for example.

This study's findings have to be viewed in the light of the following limitations. First, the experimental pretest-posttest design was ignored when the study was executed; thus, this study did not determine the actual effects of the CSCL script on the students' collaborative writing process. Regardless of this evident limitation, the study was based on an extensive qualitative data set of the students' reflective writings that were collected within various groups and contexts. Hence, the study revealed significant findings on students' insights that emerged in a parallel unique manner through incomparable group processes. Second, the data were collected from the students' individual reflection notes concerning the scripted collaborative writing process, which might not have been applied thoroughly in the collaborative process, especially at the group level. Nevertheless, the study was advantageous in indicating several potential reasons why some students experienced the proposed script as worthwhile, while others found that the script hampered them in accomplishing the collaborative writing task. Third, this study did not aim to investigate group-level interaction processes during the scripted collaboration and how these appeared to affect individual meanings and 
socially shared understandings alike. Therefore, combining these two research pathways-students' reflective texts and collaborative conversations (Krange and Ludvigsen 2008) - would be fruitful in future work. Finally, the findings were based exclusively on the students' self-reporting on the scripted collaborative writing process. Further studies might benefit from employing multiple data sources (e.g. video recordings, interviews, quantitative procedures) to gain a deeper understanding of this multidimensional phenomenon. Utilising learning analytics with students' reflective writings could also provide more robust evidence concerning the relation of the emerging collaboration process with students' experiences on scripted collaborative writing in TEL settings.

\section{Conclusion}

Our study contributes to current research by providing novel insights into university students' experiences with scripted collaborative writing in a technology-enhanced environment. First, previous studies have focused on the outcomes of students' collaboration and collaboration processes (see, e.g. the review by Vogel et al. 2017) neglecting how students actually experience the scripted collaboration and how their experiences are associated with their decisions when proceeding with the task. This present study both reveals divergent insights into 91 students' individual reflections and offers a unique view into scripted collaborative writing in CSCL environments. Second, pedagogically, an important implication of our study is that its results shed new light on the ineffectiveness of scripting (Weinberger 2008) for a particular group of students. As previous studies have established, students employ different strategies to tackle a collaborative writing task (Onrubia and Engel 2009). For example, Limbu and Markauskaite (2015, p. 398) categorise the following conceptions: '(1) the division of work to complete the task, (2) the combination of expertise to produce a good end product, (3) the fusion of ideas and insights to enable deeper understanding and (4) the development of new skills and attitudes for collaborative work'. The current study also distinguishes students' individual preferences concerning collaborative writing that seem to contribute to the decisions that they make as a group to accomplish the scripted task. This finding raises intriguing questions regarding the existence of different types of collaborative writing approaches and their relation to the optimal level of script-based support for collaborative writing tasks.

Third, our study provides an important theoretical implication. Although it is wellknown that finding a balance for optimal support is needed to avoid over-scripting or under-scripting, our results illustrate another possible kind of mismatch between the provided scripts and how the students who rejected it envisioned performing the collaborative task as a group. While over-scripting refers more to cases where students know what to do and the provided script therefore hampers them (Dillenbourg 2002; Dillenbourg and Hong 2008), scripting mismatch is linked more to group situations in which students do not see the point of either the script or the collaborative task, thus rejecting the provided script. In fact, the findings suggest some kind of mismatch between the ideal script (Papadopoulos et al. 2013), the task environment and students' ideas about the script. Following the script theory of guidance (Fischer et al. 2013b), it could be argued that students' internal scripts conflict with the external script provided, and to keep going, students need a certain level of alignment between internal and 
external scripts. Either this alignment is sufficient and they follow the actual script, or it is inadequate, and they adapt to or neglect the external script. Specifically, when the script differs too much from students' internal ideas and/or preferences (internal script), it is difficult for them to recognise the purpose of the script, and they may feel alienated from it. The experienced usefulness of the scripts could thus be argued as one of the most important predictors influencing script use. Moreover, the way that students understand the external script can influence how they appropriate and realise it to different degrees (see also Stegmann et al. 2016).

\section{Abbreviations}

CSCL: Computer-supported collaborative learning; TEL: Technology-enhanced learning; HE: Higher education;

SSICS: Simultaneous sequential integrating construction script

\section{Acknowledgements}

The authors would like to thank the participants of the study. The authors would also acknowledge the assistance of research staff at the Department of Education, University of Jyväskylä and Department of Educational Studies, Ghent University.

\section{Authors' contributions}

The initial manuscript draft was written by the first author but was reviewed and revised multiple times and complemented in conjunction with the co-authors. The data analysis was mainly executed by the first author, with the close support from the second and fifth authors. All authors participated in definitive cross-checking of the emerged results. All the authors read and approved the final manuscript.

\section{Funding}

This work was supported by the Academy of Finland [grant numbers 292466 and 318095, the Multidisciplinary Research on Learning and Teaching profiles I and II of Universty of Jyväskylä (JYU)].

\section{Availability of data and materials}

The research data is stored in the University of Jyväskylä and in the Ghent University. Due to the both universities privacy policy, the research data cannot be shared.

\section{Competing interests}

The authors declare that they have no competing interests.

\section{Author details}

${ }^{1}$ Department of Education, University of Jyväskylä, P.O. Box 35, Fl-40014 Jyvaskylä, Finland. ${ }^{2}$ Department of Educational Studies, Ghent University, Henri Dunantlaan 2, B-9000 Ghent, Belgium.

Received: 28 August 2019 Accepted: 23 March 2020

Published online: 02 July 2020

\section{References}

Arvaja, M. (2012). Personal and shared experiences as resources for meaning making in a philosophy of science Course. International Journal of Computer-Supported Collaborative Learning, 7(1), 85-108 https://doi.org/10.1007/ s11412-011-9137-5.

Arvaja, M., Salovaara, H., Häkkinen, P., \& Järvelä, S. (2007). Combining individual and group-level perspectives for studying collaborative knowledge construction in context. Learning and Instruction, 17(4), 448-459 https://doi.org/10.1016/j. learninstruc.2007.04.003.

Aydin, Z., \& Yildiz, S. (2014). Using wikis to promote collaborative EFL writing. Language Learning \& Technology, 18(1), 160180.

Braun, V., \& Clarke, V. (2006). Using thematic analysis in psychology. Qualitative Research in Psychology, 3(2), 77-101 https://doi. org/10.1191/1478088706qp063oa.

Braun, V., \& Clarke, V. (2012). Thematic analysis. In H. Cooper (Ed.), Handbook of research methods in psychology (pp. 57-71). Washington, DC: APA Books.

De Grez, N., Lämsä, J., Hämäläinen, R., Kollar, I., \& De Wever, B. (2017). How do students deal with 2 different scripts for a collaborative inquiry scientific reasoning task. Presented at the 17th Biennial EARLI Conference for Research on Learning and Instruction.

De Wever, B. (2011). Orchestrating collaborative learning in a wiki-environment. Paper presented at14th Biennial Conference for Research on Learning and Instruction (EARLI) (2011) Exeter, UK. Retrieved from https://earli.org/sites/default/files/201703/BookofAbstractsandSummaries.pdf.

De Wever, B., Hämäläinen, R., Voet, M., \& Gielen, M. (2015). A wiki task for first-year university students: The effect of scripting students' collaboration. The Internet and Higher Education, 25, 37-44 https://doi.org/10.1016/j.iheduc.2014.12.002.

Dillenbourg, P. (1999). What do you mean by 'collaborative learning'? In P. Dillenbourg (Ed.), Collaborative learning: Cognitive and computational approaches (pp. 1-16). Amsterdam: Pergamon, Elsevier Science.

Dillenbourg, P. (2002). Over-scripting CSCL: The risks of blending collaborative learning with instructional design. In P. A. Kirschner (Ed.), Three worlds of CSCL: Can we support CSCL? (pp. 61-91). Heerlen: Open University of The Netherlands. 
Dillenbourg, P., \& Hong, F. (2008). The mechanics of CSCL macro scripts. International Journal of Computer-Supported Collaborative Learning, 3(1), 5-23 https://doi.org/10.1007/s11412-007-9033-1.

Dillenbourg, P., Järvelä, S., \& Fischer, F. (2009). The evolution of research on computer-supported collaborative learning. In N. Balacheff, S. Ludvigsen, T. de Jong, A. Lazonder, \& S. Barnes (Eds.), Technology-enhanced learning (pp. 3-19). Dordrecht: Springer https://doi.org/10.1007/978-1-4020-9827-7_1.

Dillenbourg, P., \& Jermann, P. (2007). Designing integrative scripts. In F. Fischer, I. Kollar, H. Mandl, \& J. M. Haake (Eds.), Scripting computer-supported collaborative learning: Cognitive, computational, and educational perspectives (pp. 275-301). New York: Springer https://doi.org/10.1007/978-0-387-36949-5.

Dillenbourg, P., \& Tchounikine, P. (2007). Flexibility in macro scripts for computer-supported collaborative learning. Journal of Computer Assisted Learning, 23(1), 1-13 https://doi.org/10.1111/j.1365-2729.2007.00191.x.

Ede, L. S., \& Lunsford, A. A. (1990). Singular texts/plural authors : Perspectives on collaborative writing. Carbondale: Southern Illinois University Press.

Ellis, R., \& Goodyear, P. (2013). Students' experiences of e-learning in higher education: the ecology of sustainable innovation. New York: Routledge.

Ertmer, P. A., Newby, T. J., Liu, W., Tomory, A., Yu, J. H., \& Lee, Y. M. (2011). Students' confidence and perceived value for participating in cross-cultural wiki-based collaborations. Educational Technology Research and Development, 59(2), 213228.

Fischer, F., Kollar, l., Stegmann, K., \& Wecker, C. (2013b). Toward a script theory of guidance in computer-supported collaborative learning. Educational Psychologist, 48(1), 56-66 https://doi.org/10.1080/00461520.2012.748005.

Fischer, F., Kollar, l., Stegmann, K., Wecker, C., \& Zottmann, J. (2013a). Collaboration scripts in computer-supported collaborative learning. In C. E. Hmelo-Silver, C. A. Chinn, C. K. Chan, \& A. M. O'Donnell (Eds.), The international handbook of collaborative learning (pp. 403-419). New York: Routledge.

Häkkinen, P., \& Mäkitalo-Siegl, K. (2007). Educational perspectives on scripting CSCL. In F. Fischer, I. Kollar, H. Mandl, \& J. M. Haake (Eds.), Scripting computer-supported collaborative learning: Cognitive, computational and educational approaches (pp. 263-271). New York: Springer.

Hämäläinen, R. (2012). Methodological reflections: designing and understanding computer-supported collaborative learning. Teaching in Higher Education, 17(5), 603-614 https://doi.org/10.1080/13562517.2012.658556.

Hämäläinen, R., \& Häkkinen, P. (2010). Teachers instructional planning for computer-supported collaborative learning: Macroscripts as a pedagogical method to facilitate collaborative learning. Teaching and Teacher Education, 26(4), 871-877 https://doi.org/10.1016/.tate.2009.10.025.

Heimbuch, S., Ollesch, L., \& Bodemer, D. (2018). Comparing effects of two collaboration scripts on learning activities for wikibased environments. International Journal of Computer-Supported Collaborative Learning, 13(3), 331-357 https://doi.org/10. 1007/s11412-018-9283-0.

Hodges, C. G. (2002). Learning through collaborative writing. Reading, 36(1), 4-10 https://doi.org/10.1111/1467-9345.00178.

Jääskelä, P., Nykänen, S., \& Tynjälä, P. (2018). Models for the development of generic skills in Finnish higher education. Journal of Further and Higher Education, 42(1), 130-142 https://doi.org/10.1080/0309877X.2016.1206858.

Kale, U. (2014). Can they plan to teach with Web 2.0? Future teachers' potential use of the emerging web. Technology, Pedagogy and Education, 23(4), 471-489.

Kobbe, L., Weinberger, A., Dillenbourg, P., Harrer, A., Hämäläinen, R., Häkkinen, P., \& Fischer, F. (2007). Specifying computersupported collaboration scripts. International Journal of Computer-Supported Collaborative Learning, 2(2-3), 211-224. https://doi.org/10.1007/s11412-007-9014-4.

Kollar, I., \& Fischer, F. (2007). Supporting self-regulated learners for a while and what computers can contribute. Journal of Educational Computing Research, 35(4), 425-435.

Kollar, I., Fischer, F., \& Hesse, F. W. (2006). Collaboration scripts-a conceptual analysis. Educational Psychology Review, 18(2), 159-185 https://doi.org/10.1007/s10648-006-9007-2.

Krange, I., \& Ludvigsen, S. (2008). What does it mean? Students' procedural and conceptual problem solving in a CSCL environment designed within the field of science education. International Journal of Computer-Supported Collaborative Learning, 3(1), 25-51 https://doi.org/10.1007/s11412-007-9030-4.

Li, M. (2013). Individual novices and collective experts: Collective scaffolding in wiki-based small group writing. System, 41(3), 752-769 https://doi.org/10.1016/j.system.2013.07.021.

Limbu, L., \& Markauskaite, L. (2015). How do learners experience joint writing: University students' conceptions of online collaborative writing tasks and environments. Computers \& Education, 82, 393-408 https://doi.org/10.1016/..compedu. 2014.11.024.

Lowry, P. B., \& Nunamaker, J. F. (2003). Using internet-based, distributed collaborative writing tools to improve coordination and group awareness in writing teams. IEEE Transactions on Professional Communication, 46(4), 277-297 https://doi.org/ 10.1109/TPC.2003.819640.

Mackler, T. (1987). Group produced documents: An exploratory study of collaborative writing processes. (Unpublished doctoral dissertation). New York: Columbia University Teachers College.

Marttunen, M., \& Laurinen, L. (2012). Participant profiles during collaborative writing. Journal of Writing Research, 4(1), 53-79 https://doi.org/10.17239/jowr-2012.04.01.3.

Mayordomo, R. M., \& Onrubia, J. (2015). Work coordination and collaborative knowledge construction in a small group collaborative virtual task. The Internet and Higher Education, 25, 96-104 https://doi.org/10.1016/j.iheduc.2015.02.003.

Onrubia, J., \& Engel, A. (2009). Strategies for collaborative writing and phases of knowledge construction in CSCL environments. Computers \& Education, 53(4), 1256-1265 https://doi.org/10.1016/..compedu.2009.06.008.

Papadopoulos, P. M., Demetriadis, S. N., \& Weinberger, A. (2013). 'Make it explicit!': Improving collaboration through increase of script coercion. Journal of Computer Assisted Learning, 29(4), 383-398 https://doi.org/10.1111/jcal.12014.

Patton, M. Q. (2001). Qualitative evaluation and research methods (2nd ed.). Thousand Oaks: Sage Publications, Inc..

Posner, I. R., \& Baecker, R. M. (1993). How people write together. In R. M. Baecker (Ed.), Readings in groupware and computersupported cooperative work: Assisting human-human collaboration (pp. 239-250). San Mateo: Morgan Kaufmann.

Raes, A., Schellens, T., De Wever, B., \& Benoit, D. F. (2016). Promoting metacognitive regulation through collaborative problem solving on the web: When scripting does not work. Computers in Human Behavior, 58, 325-342. 
Rau, M. A., Bowman, H. A., \& Moore, J. W. (2017). An adaptive collaboration script for learning with multiple visual representations in chemistry. Computers \& Education, 109, 38-55 https://doi.org/10.1016/j.compedu.2017.02.006.

Rummel, N., \& Spada, H. (2005). Learning to collaborate: An instructional approach to promoting collaborative problem solving in computer-mediated settings. The Journal of the Learning Sciences, 14(2), 201-241.

Rummel, N., Spada, H., \& Hauser, S. (2009). Learning to collaborate while being scripted or by observing a model. International Journal of Computer-Supported Collaborative Learning, 4(1), 69-92 https://doi.org/10.1007/s11412-008-9054-4.

Sadler, T. (2004). Informal reasoning regarding socioscientific issues: A critical review of research. Journal of Research in Science Teaching, 41(5), 513-536 https://doi.org/10.1002/tea.20009.

Stegmann, K., Kollar, l., Weinberger, A., \& Fischer, F. (2016). Appropriation from a script theory of guidance perspective: A response to Pierre Tchounikine. International Journal of Computer-Supported Collaborative Learning, 11(3), 371-379 https:// doi.org/10.1007/s11412-016-9241-7.

Storch, N. (2005). Collaborative writing: Product, process, and students' reflections. Journal of Second Language Writing, 14(3), 153-173 https://doi.org/10.1016/j.jslw.2005.05.002.

Strijbos, J. W., \& Weinberger, A. (2010). Emerging and scripted roles in computer-supported collaborative learning. Computers in Human Behavior, 26(4), 491-494 https://doi.org/10.1016/j.chb.2009.08.006.

Tan, E. (2018). Effects of two differently sequenced classroom scripts on common ground in collaborative inquiry learning. Instructional Science, 46(6), 893-919 https://doi.org/10.1007/s11251-018-9460-6.

Tchounikine, P. (2016). Contribution to a theory of CSCL scripts: Taking into account the appropriation of scripts by learners. International Journal of Computer-Supported Collaborative Learning, 11(3), 349-369 https://doi.org/10.1007/s11412-0169240-8.

Vogel, F., Kollar, I., Ufer, S., Reichersdorfer, E., Reiss, K., \& Fischer, F. (2016). Developing argumentation skills in mathematics through computer-supported collaborative learning: The role of transactivity. Instructional Science, 44(5), 477-500 https:// doi.org/10.1007/s11251-016-9380-2.

Vogel, F., Wecker, C., Kollar, I., \& Fischer, F. (2017). Socio-cognitive scaffolding with computer-supported collaboration scripts: A meta-analysis. Educational Psychology Review, 29(3), 477-511 https://doi.org/10.1007/s10648-016-9361-7.

Weinberger, A. (2008). CSCL scripts: Effects of social and epistemic scripts on computer-supported collaborative learning. Berlin: VDM Verlag.

Weinberger, A., Kollar, I., Dimitriadis, Y., Mäkitalo-Siegl, K., \& Fischer, F. (2009). Computer-supported collaboration scripts. In N. Balacheff, S. Ludvigsen, T. de Jong, A. Lazonder, \& S. Barnes (Eds.), Technology-enhanced learning (pp. 155-173). Dordrecht: Springer https://doi.org/10.1007/978-1-4020-9827-7_10.

Wichmann, A., \& Rummel, N. (2013). Improving revision in wiki-based writing: Coordination pays off. Computers \& Education 62, 262-270 https://doi.org/10.1016/j.compedu.2012.10.017

\section{Publisher's Note}

Springer Nature remains neutral with regard to jurisdictional claims in published maps and institutional affiliations.

\section{Submit your manuscript to a SpringerOpen ${ }^{\circ}$ journal and benefit from:}

- Convenient online submission

- Rigorous peer review

- Open access: articles freely available online

- High visibility within the field

- Retaining the copyright to your article

Submit your next manuscript at $\boldsymbol{\nabla}$ springeropen.com 